\title{
POLYPHENOLIC PROFILE AND ANTIOXIDANT ACTIVITIES OF FREEZE-DRIED MELON MANIS TERENGGANU PEEL EXTRACTS
}

\author{
YING QIAN ONG ${ }^{1}$, SAKINAH HARITH ${ }^{1}$, MOHD RAZIF SHAHRIL ${ }^{2}$, \\ NORSHAZILA SHAHIDAN ${ }^{3 *}$ and HERMIZI HAPIDIN ${ }^{4}$ \\ ${ }^{1}$ School of Nutrition and Dietetics, Faculty of Health Sciences, Universiti Sultan Zainal Abidin, \\ Gong Badak Campus, 21300 Kuala Nerus, Terengganu, Malaysia \\ ${ }^{2}$ Nutrition Program, Center for Healthy Ageing and Wellness, Faculty of Health Sciences, \\ Universiti Kebangsaan Malaysia, Jalan Raja Muda Abdul Aziz, 50300 Kuala Lumpur, Malaysia \\ ${ }^{3}$ School of Food Industry, Faculty of Bioresources and Food Industry, Universiti Sultan Zainal Abidin, \\ Tembila Campus, 22200 Besut, Terengganu, Malaysia \\ ${ }^{4}$ Biomedicine Programme, School of Health Sciences, Health Campus, Universiti Sains Malaysia, \\ 16150 Kubang Kerian, Kelantan, Malaysia \\ *E-mail: norshazila@unisza.edu.my
}

Accepted 27 May 2021, Published online 10 June 2021

\begin{abstract}
Melon Manis Terengganu (MMT) also known as Cucumis melo var. Inodorus cv. Manis Terengganu 1 originates from Terengganu, Malaysia, is composed of $28-30 \%$ inedible peels and discarded as waste. Hence, this study aimed to quantify the polyphenol and flavonoid contents, identify polyphenolic compounds and evaluate the antioxidant activity of freezedried Melon Manis Terengganu (MMT) peel aqueous extract. The total phenolic and flavonoid contents were determined spectrophotometrically by gallic acid and quercetin standard curves, respectively. Whereas, antioxidant activity was explored by using 1,1-diphenyl-2-picrylhydrazyl (DPPH) and 2,2-azino-bis (3-ethylben-zothiazoline-6-sulfonic acid) diammonium salt (ABTS) assay. Next, liquid chromatography-mass spectrometry (LC-MS) was applied for phenolic compounds identification. Results reported that the total phenolic content was $12.35(0.59) \mu \mathrm{g}$ GAE/mg while total flavonoid content was $2.01(0.70) \mu \mathrm{g}$ QE/mg. The $\mathrm{IC}_{50}$ of DPPH and ABTS assay were $27.74(1.59) \mathrm{mg} / \mathrm{mL}$ and $4.87(0.06) \mathrm{mg} / \mathrm{mL}$, respectively. LC-MS results revealed the presence of polyphenolic compounds, such as kaempferol 3-(6"'-sinapylglucosyl)(1->2)-galactoside), isoorientin 7-O-(6"'-O-(E)-feruloyl)glucoside and isoscoparin 2'-(6-(E)-ferulylglucoside) in the sample extract. In summary, these findings served as preliminary data for further exploration on the potential application of freezedried MMT peel aqueous extract in the food and nutraceutical industry.
\end{abstract}

Key words: Antioxidant, freeze-drying, Melon Manis Terengganu peel, polyphenols

\section{INTRODUCTION}

Freeze-drying is also known as lyophilization in which water removal via sublimation from solid-state to vapor phase (Chua et al., 2019) under low temperature $\left(-2^{\circ} \mathrm{C}\right.$ to $\left.-50^{\circ} \mathrm{C}\right)$ and vacuum conditions to obtain dried products (Karam et al., 2016). Evidence suggested that freeze-drying is a preferable and widely used method to dry thermosensitive compounds, such as polyphenols, tocopherols, ascorbic acid, and carotenoids (Amaro et al., 2015) to obtain a nutritious functional food ingredient (Tumbas Šaponjac et al., 2016) by maintaining the

* To whom correspondence should be addressed. quality (Suravanichnirachorn et al., 2018). This is because thermal degradation reactions were nearly prohibited, which results in the retention of physical, chemical, and functional properties of samples (Ceballos et al., 2012; Coklar et al., 2018). However, some drawbacks are associated with freeze-drying, such as it needs longer time compared to other methods due to low drying rate, lower yield, greater energy consumption, high operation and production cost, including loss of some volatile compounds (Karam et al., 2016; Tatar Turan et al., 2015).

Surprisingly, a study revealed that worldwide more than 500 Megaton (Mt) of fruits and vegetables peel were discarded as waste during food processing (Banerjee et al., 2017). It is well-known that most of 
these wastes consisted of nutrients and bioactive compounds which can enhance human health (Ganji et al., 2019). One fruit of interest is Melon Manis Terengganu (MMT), which is recognized as Cucumis melo var. Inodorus cv. Manis Terengganu 1 and credited with antioxidant capacity, as reported by Ong et al. (2019). This is attributed to the presence of bioactive compounds, such as vitamins, polyphenol, and cucurbitacins (Amaro et al., 2015; Petkova \& Antova, 2015). Normally, MMT is peeled before consumption, which consists of $28 \%$ to $30 \%$ peel (Ong et al., 2021). Moreover, a study found that the MMT peel contained the highest epigallocatechin gallate (EGCG) concentration as compared to its flesh and seed (Ong et al., 2020). However, there is limited information about the polyphenolic profile and antioxidant capacity of MMT peel. Indeed, it is appealing to explore the novel utilization of MMT peel. Therefore, the present study aimed to quantify the polyphenol and flavonoid contents, as well as evaluate the antioxidant activities and phenolic profile of freezedried MMT peel aqueous extract.

\section{MATERIALS AND METHODS}

\section{Materials}

All chemicals and reagents used were of analytical grade. Ethanol, methanol, aluminum chloride, sodium acetate, Folin-Ciocalteau $(\mathrm{F}-\mathrm{C})$ phenol reagent were obtained from Merck (Darmstadt, Germany). Gallic acid and quercetin standards were purchased from Acros Organics (NJ, USA). Next, 1,1-diphenyl-2-picrylhydrazyl (DPPH), 2,2-azino-bis (3-ethylben-zothiazoline-6-sulfonic acid) diammonium salt (ABTS), Trolox standard, potassium persulfate, and sodium carbonate were obtained from Sigma-Aldrich (St Louis, USA. Diclofenac sodium was purchased from Sigma-Aldrich (St Louis, USA). Distilled water was purified using the Sartorius water purification system (Germany).

\section{Preparation of freeze-dried MMT peel aqueous extract}

MMT at uniform maturity stage (65 days after seeding) was collected from Mega Fertigation Farm, Kampung Telaga Papan, Setiu, in Terengganu. The peel was obtained in the form of a $\pm 0.5 \mathrm{~cm}$ thickness cut. The sample preparation, extraction, and freezedrying process were performed according to the previous procedure described (Ong et al., 2020). Briefly, the MMT peel was dried and ground into powder form followed by water extraction and freezedrying.

\section{Antioxidant activity}

The total phenolic content (TPC), total flavonoid content (TFC), DPPH, and ABTS assay were carried out following the procedure as previously outlined by Chang et al. (2002), Chatatikun and Chiabchalard (2013), Elisha et al. (2016) and Wang et al. (2018) respectively. All analyses were conducted three times.

\section{Liquid chromatography-mass spectrometry (LC-MS)}

The freeze-dried MMT peel aqueous extract was analyzed by using Agilent 1290 Infinity LC system coupled to Agilent 6520 Accurate-Mass Q-time-offlight (TOF) mass spectrometer with dual electrospray ionization (ESI) source. The HPLC separation was carried out on an Agilent Zorbax Eclipse XDB-C18, Narrow-Bore column $(2.1 \mathrm{~mm} \times 150 \mathrm{~mm}, 3.5 \mu \mathrm{m})$ operated at $25^{\circ} \mathrm{C}$. The mobile phase, which consisted of a $0.1 \%$ formic acid in water (A) and $0.1 \%$ formic acid in acetonitrile (B), was delivered at a flow rate of $0.5 \mathrm{~mL} / \mathrm{min}$ under a gradient program: $5 \%$ (B) from 0 to $5 \mathrm{~min}, 5-100 \%$ (B) from 5 to $20 \mathrm{~min}$ and $100 \%$ (B) from 20 to $25 \mathrm{~min}$. The post run time was 5 minutes. The sample injection volume was $1 \mu \mathrm{L}$ with autosampler temperature of $4^{\circ} \mathrm{C}$.

MS conceded in negative ionization mode within a mass range of $\mathrm{m} / \mathrm{z}$ 100-3200. Nitrogen was used as drying and collision gas. The heated capillary temperature was set to $300^{\circ} \mathrm{C}$ and nebulizer pressure to 45 psi. The drying gas flow rate was $10 \mathrm{~L} / \mathrm{min}$. VCap, fragmentor, skimmer and octapole RF peak voltages were set to $3500 \mathrm{~V}, 125 \mathrm{~V}, 65 \mathrm{~V}$ and $750 \mathrm{~V}$, respectively, in the ion source parameters. The chromatographic and mass spectrometric analyses, including the prediction of chemical formula and exact mass calculation were performed by using Agilent Mass Hunter Qualitative Analysis version B.07.00.

\section{Data analysis}

The research data were analyzed by using IBM SPSS for Windows Version 21.0. The data were assessed by descriptive analysis and presented as mean and standard deviation.

\section{RESULTS AND DISCUSSION}

As can be seen from Table 1, TPC of MMT peel aqueous extract was $12.35(0.59) \mu \mathrm{g}$ GAE/mg identified via a linear gallic acid standard curve $\left(\mathrm{y}=0.0111 \mathrm{x}+0.0868, \mathrm{R}^{2}=0.9493\right)$. Meanwhile, quercetin standard curve with $\mathrm{y}=0.0089 \mathrm{x}+0.016$ and $\mathrm{R}^{2}=0.9914$ was used to determine TFC of 2.01 (0.70) $\mu \mathrm{g}$ QE/mg. TPC of freeze-dried MMT peel 
Table 1. Polyphenolic content and antioxidant activity of freeze-dried MMT peel aqueous extract ( $n=3)$

\begin{tabular}{|c|c|}
\hline Antioxidant activities & Readings \\
\hline Total phenolic content ( $\mu \mathrm{g}$ GAE/mg) & $12.35(0.59)$ \\
\hline Total flavonoid content ( $\mu \mathrm{g} Q E / m g)$ & $2.01(0.70)$ \\
\hline 1,1-diphenyl-2-picrylhydrazyl (DPPH) assay $I_{50}(\mathrm{mg} / \mathrm{mL})$ & $27.74(1.59)$ \\
\hline 2,2-azino-bis (3-ethylben- zothiazoline-6-sulfonic acid) diammonium salt (ABTS) assay $I_{50}(\mathrm{mg} / \mathrm{mL})$ & $4.87(0.06)$ \\
\hline
\end{tabular}

Data are reported as mean (SD).

aqueous extract was greater as compared to previous studies $(0.14 \pm 0.01 \mu \mathrm{g} \mathrm{GAE} / \mathrm{mg}$ in Cucumis melo L. var. reticulatus by Fundo et al., 2018; $0.69 \pm 0.06$ to $2.96 \pm 0.12 \mu \mathrm{g} \mathrm{GAE} / \mathrm{mg}$ by Ganji et al., 2019; $4.70 \pm$ $0.23 \mu \mathrm{g} \mathrm{GAE} / \mathrm{mg}$ in Cucumis melo L. var. reticulatus by Ismail et al., 2010; $3.32 \pm 0.00 \mu \mathrm{g} \mathrm{GAE} / \mathrm{mg}$ in Cucumis melo L. cv. maazoun by Mallek-Ayadi et al., 2016; $8.47 \pm 0.21 \mu \mathrm{g} \mathrm{GAE} / \mathrm{mg}$ in Cucumis melo var. cantalupensis by Marwa \& Hany, 2016; $2.27 \pm 0.42$ $\mu \mathrm{g}$ GAE/mg by Morais et al., 2015; $1.11 \pm 0.15 \mu \mathrm{g}$ $\mathrm{GAE} / \mathrm{mg}$ in Cucumis melo L. var. reticulatus by Rolim et al., 2018; $0.23 \pm 0.01 \mu \mathrm{g}$ GAE $/ \mathrm{mg}$ in muskmelon by Singh et al., 2016) and two-fold lower than that of a study byVella et al. (2019) which reported 25.48 $\mu \mathrm{g}$ GAE/mg in Cucumis melo L. var. reticulatus Meanwhile, the TFC of freeze-dried MMT peel aqueous extract was higher than previous studies by three to 30 folds $(0.95 \pm 0.00 \mu \mathrm{g}$ QE/mg in Cucumis melo L. cv. maazoun by Mallek-Ayadi et al., 2016; $2.00 \pm 0.60 \mu \mathrm{g} \mathrm{QE} / \mathrm{mg}$ by Morais et al., 2015; $0.06 \pm$ $0.00 \mu \mathrm{g} \mathrm{QE} / \mathrm{mg}$ in muskmelon by Singh et al., 2016). The discrepancies of polyphenolic contents could be attributed to several factors such as maturation level during harvesting (Rodríguez-Pérez et al., 2013), edaphic factors (soil conditions, sunlight exposure, and rainfall) (Rolim et al., 2019), growing region (Jakobek et al., 2013), growing seasons, genotype or cultivar (Tadmor et al., 2010), cultural practices (Miletić et al., 2012) as well as ambient conditions of previous harvests, post-harvest, and processing (Pandey \& Rizvi, 2009). Besides, the gap could be due to the differences in drying and extraction conditions. In this study, the possible factors contributed to these differences might be due to the varied types of melon, drying and extraction parameters.

Next, the antioxidant activity of MMT peel aqueous extract was determined by DPPH and ABTS assay in terms of $\mathrm{IC}_{50}$ with $27.74(1.59) \mathrm{mg} / \mathrm{mL}$ and $4.87(0.06) \mathrm{mg} / \mathrm{mL}$, respectively. Nevertheless, the $\mathrm{IC}_{50}$ remains lower as compared to the standard (quercetin), with an $\mathrm{IC}_{50}$ of $0.02(0.00) \mathrm{mg} / \mathrm{mL}$ in $\mathrm{DPPH}$ assay, and standard (Trolox) with an $\mathrm{IC}_{50}$ of 0.06 (0.00) $\mathrm{mg} / \mathrm{mL}$ in ABTS assay. Otherwise, the MMT peel aqueous extract scavenge DPPH and ABTS radicals in a dose-dependent manner, with inhibition being greater than $81 \%$ at $50 \mathrm{mg} / \mathrm{mL}$ (Figure 1) and $86 \%$ at $6 \mathrm{mg} / \mathrm{mL}$ (Figure 2), respectively. The $\mathrm{IC}_{50}$ of the DPPH assay in this study was lower than other studies $(9.58 \pm 0.37 \mathrm{mg} / \mathrm{mL}$ in Cucumis melo L. var. reticulatus by Ismail et al., 2010; $0.19 \pm 0.00 \mathrm{mg} / \mathrm{mL}$ by Morais et al., $2015 ; 0.32$ to $0.50 \mathrm{mg} / \mathrm{mL}$ in rockmelon by Norrizah et al., 2012; $6.65 \mathrm{mg} / \mathrm{mL}$ in Cucumis melo L. var. reticulatus by Vella et al., 2019; 0.0046 to $0.0053 \mathrm{mg} / \mathrm{mL}$ by Wakid \& Harun, 2020). Normally, the inhibition of $\mathrm{ABTS}^{++}$activity is usually used to confirm with DPPH ${ }^{-}$scavenging capacity since both are similar in their antioxidant mechanisms in which both radicals can receive electrons and $\mathrm{H}^{\circ}$ from the antioxidant samples (Singh et al., 2016; Santos-Sánchez et al., 2019). In this study, the $\mathrm{IC}_{50}$ of ABTS was lower than that of DPPH. One possible explanation for this discrepancy could be attributed to the difference in the antioxidant action of the assay (Nayak et al., 2015). The reaction of antioxidants with ABTS radical is much faster than DPPH radical. The slow and fast reactions of antioxidants with ABTS radical can attain a steadystate within $6 \mathrm{~min}$. Meanwhile, the fast, intermediate, and slow reactions of antioxidants with DPPH radical need 0 to $5 \mathrm{~min}, 5$ to $30 \mathrm{~min}$, and more than $30 \mathrm{~min}$, respectively, to attain the steady-state. In this study, the incubation time covered both slow and fast reactions in ABTS assay, but only fast and intermediate reactions in DPPH assay. Indirectly, the results implied that the freeze-dried MMT peel aqueous extract may contain considerable slowacting antioxidants towards DPPH radical (Yang et al., 2011).

Freeze-drying is one of the most effective methods to preserve thermo-labile bioactive compounds better as compared to other drying methods (Zori et al., 2016; Coklar et al., 2018). Extensive research demonstrated that greater total phenolic, tannin, and flavonoid contents were found in samples subjected to freeze-drying such as in pomegranate peel (Mphahlele et al., 2016), pomegranate rind (Calín-Sánchez et al., 2013), and persimmon (Karaman et al., 2014). Phenolics and flavonoids are considered as plants' secondary metabolites which take part in a complex system of antioxidant defense via free radical scavenging 


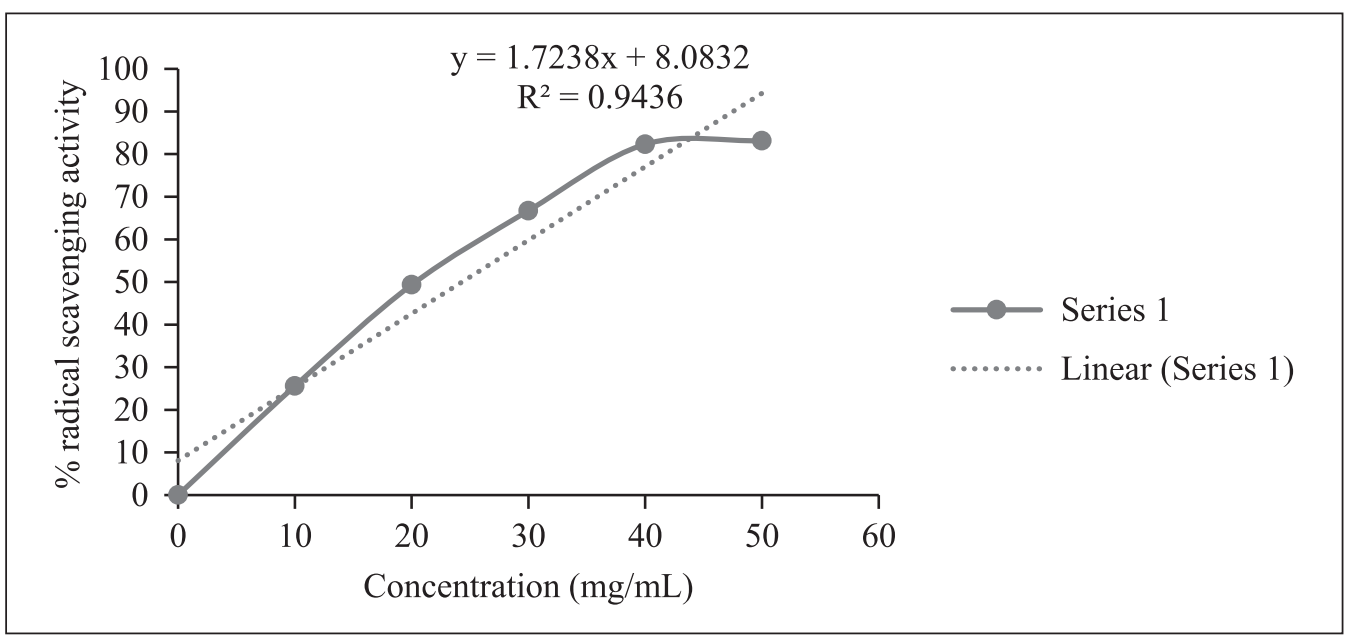

Fig. 1. DPPH radical scavenging activity of freeze-dried MMT peel aqueous extract.

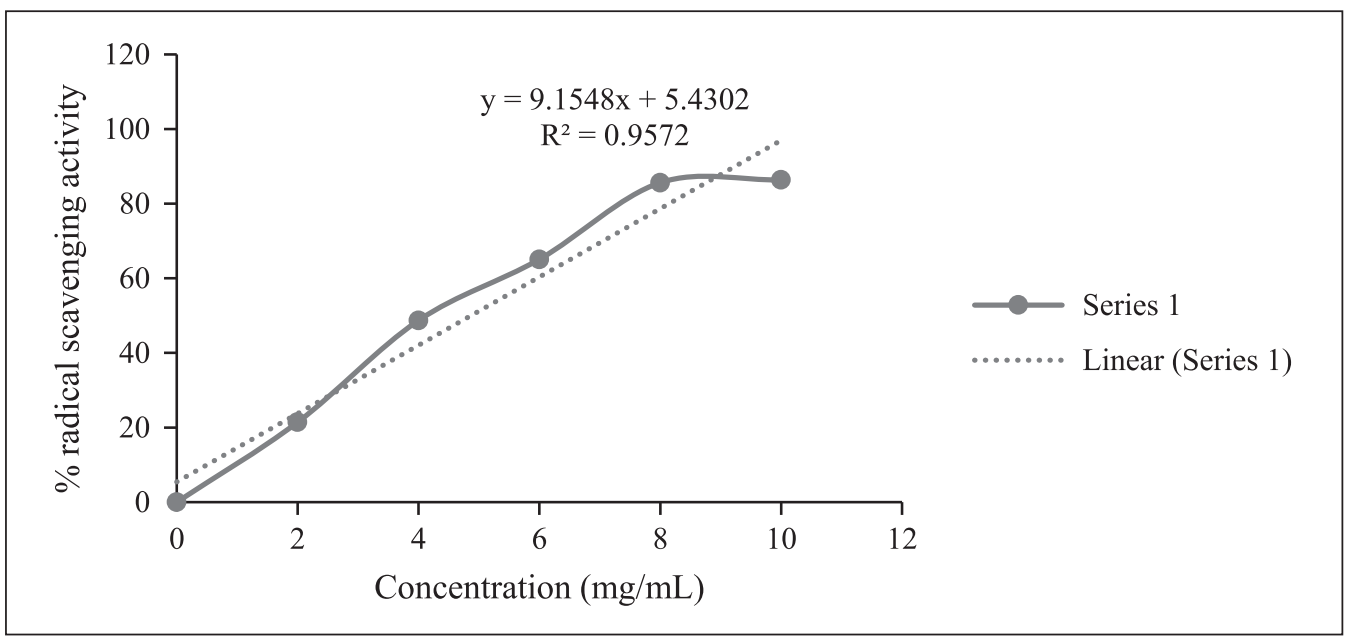

Fig. 2. ABTS radical scavenging activity of freeze-dried MMT peel aqueous extract.

activity, chelation of transition metals, suppression of pro-oxidative enzymes (Bouaziz et al., 2020), and synergistic interaction with other antioxidants (Andreicut et al., 2018). Literature reports that the shikimate (shikimic acid) biosynthetic pathway is involved in the generation of the aromatic melon compounds which seem to be responsible for the antioxidant properties of the melon peel (Ismail et al., 2010). Polyphenols are also recognized as potent antioxidant compounds with higher free radical scavenging activity as compared to vitamin $\mathrm{C}$ and vitamin E (Coklar et al., 2018). It is also well established that phenolic compounds, particularly flavonoids, are responsible for free radical scavenging activity. However, it should be noted that antioxidant activity does not depend solely on phenolic content, but is also influenced by other compounds, such as ascorbic acid, flavonoid, and carotenoid (Wulandari et al., 2017).

As for the identification of phenolic compounds by LC-MS, different $\mathrm{m} / \mathrm{z}$ values were detected
(Table 2) with three compounds deduced based on their molecular structures (Figure 3). The identified phenolic compounds were classified into flavonol group (kaempferol 3-(6"'-sinapylglucosyl)-(1$>2$ )-galactoside) and flavone group (isoorientin 7-O(6"'-O-(E)-feruloyl)glucoside and isoscoparin 2' -(6(E)-ferulylglucoside)). These bioactive compounds belong to derivatives of kaempferol, isoorientin, and isoscoparin. A previous study also demonstrated that the cantaloupe melon peel contained kaempferol (Vella et al., 2019). Kaempferol exhibited various beneficial health effects, such as antioxidant (Arif et al., 2018; Wang et al., 2018), anti-inflammatory (Wang et al., 2018; Nascimento et al., 2017), antidiabetic (Li et al., 2017), and anti-arthritic (Zhuang et al., 2017; Huang et al., 2018) properties. Next, isoorientin also had the potential to act as an antioxidant (Yuan et al., 2016) and anti-inflammatory (Anilkumar et al., 2017) agent based on previously reported studies. Last but not least, previous research also claimed isoscoparin possesses antioxidant 
Table 2. LC-MS of freeze-dried MMT peel aqueous extract

\begin{tabular}{cccc}
\hline Retention time $(\mathrm{min})$ & $\mathrm{m} / \mathrm{z}[\mathrm{M}-\mathrm{H}]^{-}$ & Molecular formula & Compound identification \\
\hline 8.555 & 815.2054 & C38 H40 O20 & Kaempferol 3-(6"'-sinapylglucosyl)-(1->2)-galactoside \\
8.802 & 786.2022 & C37 H38 O19 & Isoorientin 7-O-(6"'-O-(E)-feruloyl)glucoside \\
8.999 & 799.2104 & C38 H40 O19 & Isoscoparin 2"-(6-(E)-ferulylglucoside) \\
\hline
\end{tabular}

(a)

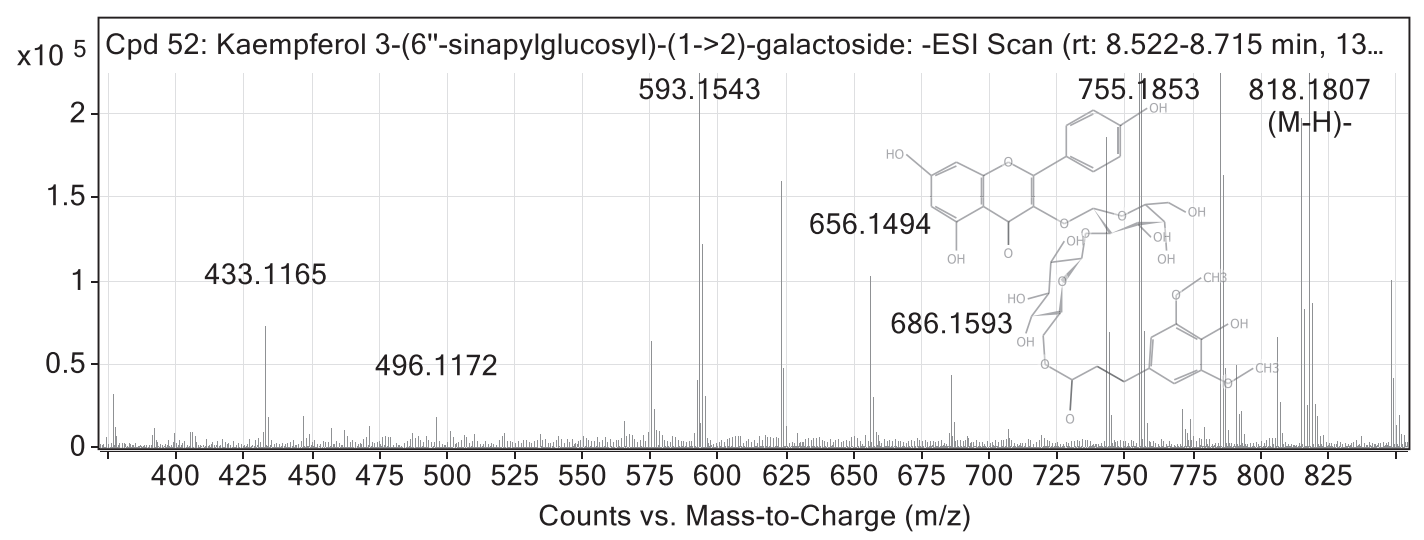

(b)

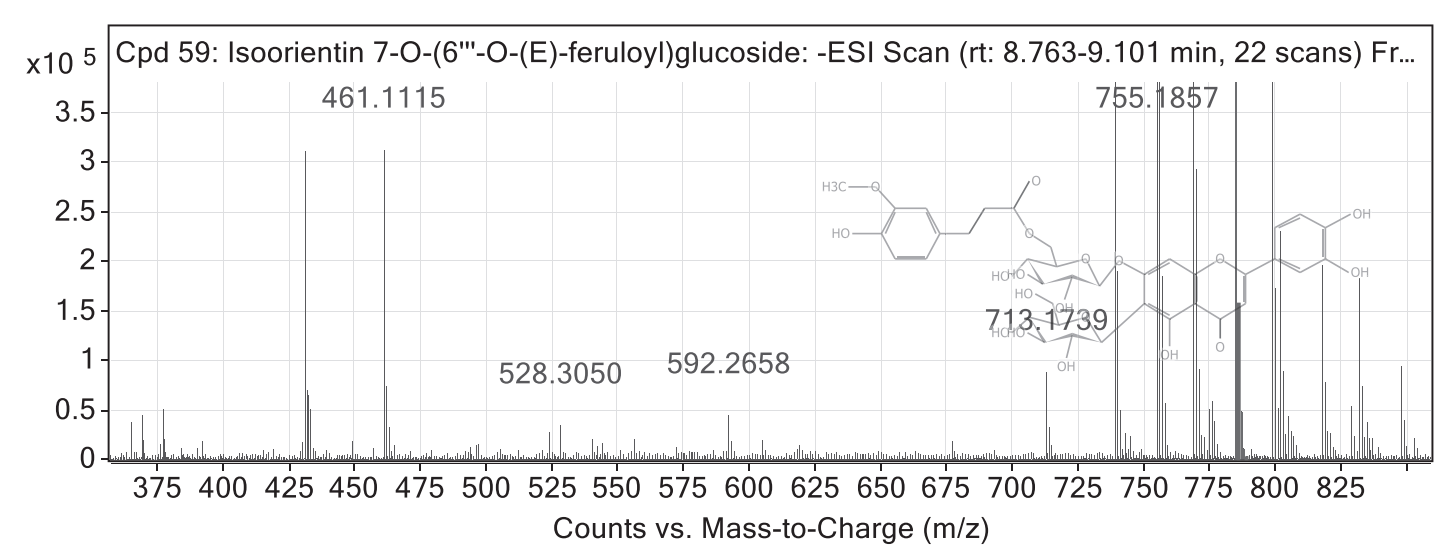

(c)

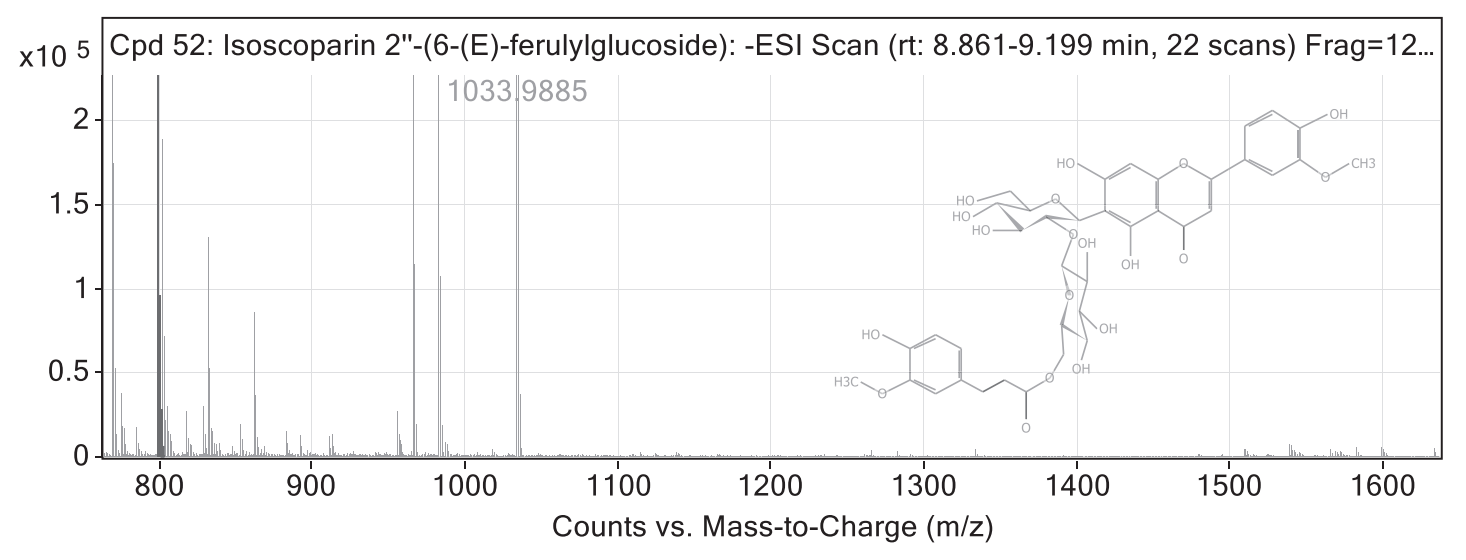

Fig. 3. MS spectrum of a) kaempferol 3-(6'"-sinapylglucosyl)-(1->2)-galactoside b) isoorientin 7-O-(6'"'-O-(E)feruloyl)glucoside and c) isoscoparin 2''-(6-(E)-ferulylglucoside). 
and anti-inflammatory capacity (Yang et al., 2016). These properties are beneficial to osteoarthritis, as reported by a scoping review (Ong et al., 2020). To conclude, the antioxidant properties showed by the freeze-dried MMT peel aqueous extract in this study could be attributed to the presence of these bioactive compounds.

\section{CONCLUSION}

The freeze-dried MMT peel aqueous extract contains antioxidant properties with the presence of polyphenolic compounds. These findings served as preliminary data for further exploration on the potential application of freeze-dried MMT peel aqueous extract in the food and nutraceutical industry. Further studies on MMT peel aqueous extract are warranted to identify the exact mechanism of action for its antioxidant properties.

\section{ACKNOWLEDGEMENTS}

This study was funded by the Ministry of Education, Malaysia under the Fundamental Research Grant Scheme (FRGS/1/2018/TK02/UNISZA/03/1). The authors would like to extend their gratitude to the LCMS Lab located in Monash University Malaysia for assisting LCMS. The authors are indebted to everyone who has contributed to this research.

\section{REFERENCES}

Amaro, A.L., Oliveira, A. \& Almeida, D.P.F. 2015. Biologically active compounds in melon: Modulation by preharvest, post-harvest, and processing factors. In Processing and Impact on Active Components in Food. R.P. Victor (Ed.). Academic Press, London. pp. 165-171.

Andreicut, A.D., Pârvu, A.E., Mot, A.C., Pârvu, M., Fodor, E.F., CÎtoi, A.F., Feldrihan, V., Cecan, M. \& Irimie, A. 2018. Phytochemical analysis of antiinflammatory and antioxidant effects of Mahonia aquifolium flower and fruit extracts. Oxidative Medicine and Cellular Longevity, 2018: Article ID 2879793.

Anilkumar, K., Reddy, G.V., Azad, R., Yarla, N.S., Dharmapuri, G., Srivastava, A., Kamal, M.A. \& Pallu, R. 2017. Evaluation of anti-inflammatory properties of isoorientin isolated from tubers of Pueraria tuberosa. Oxidative Medicine and Cellular Longevity, 2017: Article ID 5498054.

Arif, H., Sohail, A., Farhan, M., Rehman, A.A., Ahmad, A. \& Hadi, S.M. 2018. Flavonoidsinduced redox cycling of copper ions leads to generation of reactive oxygen species: A potential role in cancer chemoprevention. International Journal of Biological Macromolecules, 106: 569-578.

Banerjee, J., Singh, R., Vijayaraghavan, R., MacFarlane, D., Patti, A.F. \& Arora, A. 2017. Bioactives from fruit processing wastes: Green approaches to valuable chemicals. Food Chemistry, 225: 10-22.

Bouaziz, A., Djidel, S., Bentaher, A. \& Khennouf, S. 2020. Polyphenolic content, antioxidant and antiinflammatory activities of melon (Cucumis melo L. var. inodorus) seeds. Journal of Drug Delivery and Therapeutics, 10(2-s): 22-26.

Calín-Sánchez, Á., Figiel, A., Hernández, F., Melgarejo, P., Lech, K. \& Carbonell-Barrachina, Á.A. 2013. Chemical composition, antioxidant capacity, and sensory quality of pomegranate (Punica granatum L.) arils and rind as affected by drying method. Food and Bioprocess Technology, 6(7): 1644-1654.

Ceballos, A.M., Giraldo, G.I. \& Orrego, C.E. 2012. Effect of freezing rate on quality parameters of freeze dried soursop fruit pulp. Journal of Food Engineering, 111(2): 360-365.

Chang, L.W., Yen, W.J., Huang, S.C. \& Duh, P.D. 2002. Antioxidant activity of sesame coat. Food Chemistry, 78(3): 347-354.

Chatatikun, M. \& Chiabchalard, A. 2013. Phytochemical screening and free radical scavenging activities of orange baby carrot and carrot (Daucus carota Linn.) root crude extracts. Journal of Chemical and Pharmaceutical Research, 5(4): 97-102.

Chua, L.Y.W., Chong, C.H., Chua, B.L. \& Figiel, A. 2019. Influence of drying methods on the antibacterial, antioxidant and essential oil volatile composition of herbs: A review. Food and Bioprocess Technology, 12(3): 450-476.

Coklar, H., Akbulut, M., Kilinc, S., Yildirim, A. \& Alhassan, I. 2018. Effect of freeze, oven and microwave pretreated oven drying on color, browning index, phenolic compounds and antioxidant activity of hawthorn (Crataegus orientalis) fruit. Notulae Botanicae Horti Agrobotanici Cluj-Napoca, 46(2): 449-456.

Elisha, I.L., Dzoyem, J., Mcgaw, L.J., Botha, F.S. \& Eloff, J.N. 2016. The anti-arthritic, antiinflammatory, antioxidant activity and relationships with total phenolics and total flavonoids of nine South African plants used traditionally to treat arthritis. BMC Complementary and Alternative Medicine, 16(307): 1-10.

Fundo, J.F., Miller, F.A., Garcia, E., Santos, J.R., Silva, C.L.M. \& Brandão, T.R.S. 2018. Physicochemical characteristics, bioactive compounds and antioxidant activity in juice, pulp, peel and seeds of Cantaloupe melon. Journal of Food Measurement and Characterization, 12(1): 292-300. 
Ganji, S.M., Singh, H. \& Friedman, M. 2019. Phenolic content and antioxidant activity of extracts of 12 melon (Cucumis melo) peel powders prepared from commercial melons. Journal of Food Science, 84(7): 1943-1948.

Huang, X., Pan, Q., Mao, Z., Wang, P., Zhang, R., Ma, X., Chen, J. \& You, H. 2018. Kaempferol inhibits interleukin-1ß stimulated matrix metalloproteinases by suppressing the MAPKassociated ERK and P38 signaling pathways. Molecular Medicine Reports, 18(3): 2697-2704.

Ismail, H.I., Chan, K.W., Mariod, A.A. \& Ismail, M. 2010. Phenolic content and antioxidant activity of cantaloupe (Cucumis melo) methanolic extracts. Food Chemistry, 119(2): 643-647.

Jakobek, L., García -Villalba, R. \& Tomás-Barberán, F. 2013. Polyphenolic characterisation of old local apple varieties from Southeastern European region. Journal of Food Composition and Analysis, 31(2): 199-211.

Karam, M.C., Petit, J., Zimmer, D., Baudelaire Djantou, E. \& Scher, J. 2016. Effects of drying and grinding in production of fruit and vegetable powders: A review. Journal of Food Engineering, 188: 3249.

Karaman, S., Toker, O.S., Çam, M., Hayta, M., Doçan, M. \& Kayacier, A. 2014. Bioactive and physicochemical properties of persimmon as affected by drying methods. Drying Technology, 32(3): 258-267.

Li, F., Zhang, B., Chen, G. \& Fu, X. 2017. The novel contributors of anti-diabetic potential in mulberry polyphenols revealed by UHPLC-HRESI-TOF-MS/MS. Food Research International, 100(Pt 1): 873-884.

Mallek-Ayadi, S., Bahloul, N. \& Kechaou, N. 2016. Characterization, phenolic compounds and functional properties of Cucumis melo L. peels. Food Chemistry, 221: 1691-1697.

Marwa, E.E.D.I. \& Hany, G.E.M. 2016. Phenolic content and antioxidant activity of cantaloupe (Cucumis melo var. cantalupensis) and food application. International Journal of Nutrition and Food Sciences, 5(1): 16-24.

Miletić, N., Popoviæ, B., Mi, O. \& Kandiæ, M. 2012. Phenolic content and antioxidant capacity of fruits of plum cv. 'Stanley' (Prunus domestica L.) as influenced by maturity stage and on-tree ripening. Australian Journal of Crop Science, 6(4): 681-687.

Morais, D.R., Rotta, E.M., Sargi, S.C., Schmidt, E.M., Guntendorfer, E., Eberlin, M.N., Sawaya, A.C.H.F. \& Visentainer, J.V. 2015. Antioxidant activity, phenolics and UPLC-ESI (-)-MS of extracts from different tropical fruits parts and processed peels. Food Research International, 77(3): 392399.
Mphahlele, R.R., Fawole, O.A., Makunga, N.P. \& Opara, U.L. 2016. Effect of drying on the bioactive compounds, antioxidant, antibacterial and antityrosinase activities of pomegranate peel. BMC Complementary and Alternative Medicine, 16: $1-12$.

Nascimento, A.M., Maria-Ferreira, D., Dal Lin, F.T., Kimura, A., de Santana-Filho, A.P., Werner, M.F. de P., Iacomini, M., Sassaki, G.L., Cipriani, T.R. \& de Souza, L.M. 2017. Phytochemical analysis and anti-inflammatory evaluation of compounds from an aqueous extract of Croton cajucara Benth. Journal of Pharmaceutical and Biomedical Analysis, 145: 821-830.

Nayak, B., Liu, R.H. \& Tang, J. 2015. Effect of processing on phenolic antioxidants of fruits, vegetables, and grains - A review. Critical Reviews in Food Science and Nutrition, 55(7): 887-918.

Norrizah, J.S., Hashim, S.N., Siti Fasiha, F. \& Yaseer, S.M. 2012. $\beta$-carotene and antioxidant analysis of three different rockmelon (Cucumis melo L.) cultivars. Journal of Applied Sciences, 12(17): 1846-1852.

Ong, Y.Q., Sakinah, H., Shahril, M.R. \& Norshazila, S. 2019. Bioactive compounds in Cucumis melo L. and its beneficial health effects: A scoping review. Malaysian Applied Biology, 48(4): 1123.

Ong, Y.Q., Sakinah, H., Shahril, M.R. \& Norshazila, S. 2020. Antioxidant and anti-inflammatory dietary supplements in the treatment of osteoarthritis: A scoping review. Food Research, 4(2): 254-273.

Ong, Y.Q., Sakinah, H., Shahril, M.R., Norshazila, S. \& Sia, S.Y. 2020. Quantification of epigallocatechin gallate in Melon Manis Terengganu (Cucumis melo L.) by high performance liquid chromatography. Bioscience Research, 17(2): 1129-1137.

Ong, Y.Q., Sakinah, H., Shahril, M.R., Norshazila, S. \& Hermizi, H. 2021. Determination of vitamins, minerals, heavy metals and anti-inflammatory activity of Melon Manis Terengganu peel. Bioscience Research, 18(1): 1131-1139.

Pandey, K.B. \& Rizvi, S.I. 2009. Plant polyphenols as dietary antioxidants in human health and disease. Oxidative Medicine and Cellular Longevity, 2(5): 270-278.

Petkova, Z. \& Antova, G. 2015. Proximate composition of seeds and seed oils from melon (Cucumis melo L.) cultivated in Bulgaria. Cogent Food \& Agriculture, 1: 1018779.

Rodríguez-Pérez, C., Quirantes-Piné, R., FernándezGutiérrez, A. \& Segura-Carretero, A. 2013. Comparative characterization of phenolic and other polar compounds in Spanish melon 
cultivars by using high-performance liquid chromatography coupled to electrospray ionization quadrupole-time of flight mass spectrometry. Food Research International, 54(2): 1519-1527.

Rolim, P.M., Fidelis, G.P., Padilha, C.E.A.A., Santos, E.S., Rocha, H.A.O.O. \& Macedo, G.R. 2018. Phenolic profile and antioxidant activity from peels and seeds of melon (Cucumis melo L. var. reticulatus) and their antiproliferative effect in cancer cells. Brazilian Journal of Medical and Biological Research, 51(4): e6069.

Rolim, P.M., Seabra, L.M.J. \& de Macedo, G.R. 2019. Melon by-products: Biopotential in human health and food processing. Food Reviews International, 1-24.

Santos-Sánchez, N.F., Salas-Coronado, R., VillanuevaCañongo, C. \& Hernández-Carlos, B. 2019. Antioxidant compounds and their antioxidant mechanism. Antioxidants, 1-28.

Singh, J., Singh, V., Shukla, S. \& Rai, K.A. 2016. Phenolic content and antioxidant capacity of selected cucurbit fruits extracted with different solvents. Journal of Nutrition \& Food Sciences, 6: 565 .

Suravanichnirachorn, W., Haruthaithanasan, V., Suwonsichon, S., Sukatta, U., Maneeboon, T. \& Chantrapornchai, W. 2018. Effect of carrier type and concentration on the properties, anthocyanins and antioxidant activity of freezedried mao [Antidesma bunius (L.) Spreng] powders. Agriculture and Natural Resources, 52(4): 354-360.

Tadmor, Y., Burger, J., Yaakov, I., Feder, A., Libhaber, S.E., Portnoy, V., Meir, A., Tzuri, G., Sa'ar, U., Rogachev, I., Aharoni, A., Abeliovich, H., Schaffer, A.A., Lewinsohn, E. \& Katzir, N. 2010. Genetics of flavonoid, carotenoid, and chlorophyll pigments in melon fruit rinds. Journal of Agricultural and Food Chemistry, 58: 10722-10728.

Tatar Turan, F., Cengiz, A. \& Kahyaoglu, T. 2015. Evaluation of ultrasonic nozzle with spray-drying as a novel method for the microencapsulation of blueberry's bioactive compounds. Innovative Food Science and Emerging Technologies, 32: 136-145.

Tumbas Šaponjac, V., Ćetković, G., CanadanovicBrunet, J., Pajin, B., Djilas, S., Petrović, J., Lonèarević, I., Stajèić, S. \& Vuliæ, J. 2016. Sour cherry pomace extract encapsulated in whey and soy proteins: Incorporation in cookies. Food Chemistry, 207: 27-33.

Vaijayanthimala, P., Sakthipriya, M. \& Sangameswaran, B. 2019. In vitro anti-arthritic activity of Cissus quadrangularis stem extract. Asian Journal of Pharmaceutical and Clinical Research, 12(1): 250.
Vella, F.M., Cautela, D. \& Laratta, B. 2019. Characterization of polyphenolic compounds in cantaloupe melon by-products. Foods, 8(6): 196.

Vella, F.M., Laratta, B., La Cara, F. \& Morana, A. 2018. Recovery of bioactive molecules from chestnut (Castanea sativa Mill.) by-products through extraction by different solvents. Natural Product Research, 32(9): 1022-1032.

Wakid, S.A. \& Harun, H.A. 2020. Antioxidant activity of melon fruit peel extracts. Journal of Academia, 8(1): 53-57.

Wang, J., Fang, X., Ge, L., Cao, F., Zhao, L., Wang, Z. \& Xiao, W. 2018. Antitumor, antioxidant and anti-inflammatory activities of kaempferol and its corresponding glycosides and the enzymatic preparation of kaempferol. PLOS ONE, 13(5).

Wang, Y., Qi, D., Wang, S., Cao, X., Ye, Y. \& Suo, Y. 2018. Comparison of phenols content and antioxidant activity of fruits from different maturity stages of Ribes stenocarpum Maxim. Molecules, 23: 3148.

Wulandari, P., Daryono, B.S. \& Supriyadi. 2017. The effect of ripening stages on the antioxidant potential of melon (Cucumis melo L.) cultivar Hikapel. AIP Conference Proceedings, 1854: 020039.

Yang, J., Gadi, R. \& Thomson, T. 2011. Antioxidant capacity, total phenols, and ascorbic acid content of noni (Morinda citrifolia) fruits and leaves at various stages of maturity. Micronesica, 41(2): 167-176.

Yang, Z., Nakabayashi, R., Mori, T., Takamatsu, S., Kitanaka, S. \& Saito, K. 2016. Metabolome analysis of Oryza sativa (rice) using liquid chromatography-mass spectrometry for characterizing organ specificity of flavonoids with antiinflammatory and anti-oxidant activity. Chemical and Pharmaceutical Bulletin, 64(7): 952-956.

Yuan, L., Wang, J., Wu, W., Liu, Q. \& Liu, X. 2016. Effect of isoorientin on intracellular antioxidant defence mechanisms in hepatoma and liver cell lines. Biomedicine and Pharmacotherapy, 81: 356-362.

Zhuang, Z., Ye, G. \& Huang, B. 2017. Kaempferol alleviates the interleukin-1 $\beta$-induced inflammation in rat osteoarthritis chondrocytes via suppression of NF-кB. Medical Science Monitor, 23: 3925-3931.

Zori, Z., Pedisi, S., Bursa, D. \& Je, D. 2016. Impact of packaging material and storage conditions on polyphenol stability, colour and sensory characteristics of freeze-dried sour cherry (Prunus cerasus var. Marasca ). Journal of Food Science and Engineering, 53(2): 1247-1258. 